\title{
Congenital Malformations in Denmark: Considerations for the Use of Danish Health Care Registries
}

This article was published in the following Dove Press journal: Clinical Epidemiology

\author{
Anne Broe (iD) ${ }^{1,2}$ \\ Per Damkier (iD) 1,2 \\ Anton Pottegård (iD ${ }^{3}$ \\ Jesper Hallas (iD) ${ }^{1,3}$ \\ Mette Bliddal iD ${ }^{3,4}$ \\ 'Department of Clinical Biochemistry \\ and Pharmacology, Odense University \\ Hospital, Odense, Denmark; \\ ${ }^{2}$ Department of Clinical Research, \\ University of Southern Denmark, \\ Odense, Denmark; ${ }^{3}$ Department of \\ Clinical Pharmacology, Pharmacy, and \\ Environmental Medicine, University of \\ Southern Denmark, Odense, Denmark; \\ ${ }^{4}$ Department of Clinical Research, Open \\ Patient Data Explorative Network, \\ University of Southern Denmark and \\ Odense University Hospital, Odense, \\ Denmark
}

Background: Danish health registers are used widely to examine associations between specific risk factors and congenital malformations. Various overall prevalence rates of malformations have been reported in Denmark indicating differences in the underlying data sources or malformation definitions. We described trends in registration of malformations in Denmark 1997-2017 and identified potential caveats for the use of Danish health registries in epidemiological studies. We composed a Danish adaptation of EUROCATs definition of malformations.

Methods: Using nationwide Danish health registries, we identified all recorded pregnancies and followed livebirths for up to 5 years. We described the different data sources, ways to identify malformations, the overall rate of malformations over time, and identified the 10 most common major malformations.

Results: A total of 1,340,774 foetuses and infants from 1,313,281 pregnancies among 747,144 women from 1997 to 2017 were analysed. Using primary and secondary diagnoses from all available sources and restricting hip malformations to diagnoses after 6 weeks postpartum, we found that 65,411 (49/1000) foetuses or infants had at least one major malformation defined by our Danish translation of EUROCATs definition of malformations. The prevalence of major malformations increased over time from 39/1000 in 1997 to 53/1000 in 2017. The most common specific malformations were malformations of cardiac septa (Q21) and great arteries (Q25) with a peak of 10 and 6/1000 births in 2010 and 2009, respectively.

Conclusion: Malformations should be identified using primary and secondary diagnoses from the Birth register, the Patient register, and the Cause of Death register. To increase transparency and external validity, classification of major malformations should be based on the Danish adaptation of EUROCATs classification of malformations.

Keywords: malformations, anomalies, health registries, epidemiology, EUROCAT

\section{Introduction}

The nationwide Danish health registers are used widely to study how specific risk factors are associated with congenital malformations. ${ }^{1-11}$ In such studies, it is essential to have insights in characteristics of malformations and trends over time, which again rely on the completeness and the validity of malformation registrations within the registers. A systematic description of available data and a guide to use these have not been made in Denmark.

Various overall prevalence rates of malformations in Denmark have been reported ranging from $3.2 \%$ to $6.0 \%{ }^{7,8}$ These varying estimates indicate
Correspondence: Anne Broe

Department of Clinical Biochemistry \&

Pharmacology, Odense University

Hospital, JB Winsløwsvej 19, 2, Odense

5000 Odense C, Denmark

Email anbroe@health.sdu.dk
Clinical Epidemiology 2020:12 137|-1380 
differences in either the underlying data sources used, the definition of major malformations that are applied, or study periods.

In 2019, the Danish Health Authorities reported a doubling in registered prevalence of any congenital malformations among livebirths from $4.3 \%$ in 1997 to $8.1 \%$ in $2016 .{ }^{12}$ The authorities had implemented major changes in antenatal care, including enhanced screening by ultrasound scans with improved equipment and professional knowledge. Such factors contribute to improved prenatal diagnostics of malformations and better treatment in early life. In addition to this, coding practices have changed over time and the influence from this to data validity has not been systematically assessed. ${ }^{13-15}$ Whether the registered increase reflects a true increased incidence and prevalence of congenital malformations thus remains unclear.

In 1979, the European Commission set up a data repository to monitor congenital malformations in Europe (EUROCAT). ${ }^{16}$ Overall, EUROCAT data report a slightly increasing prevalence rate of congenital malformations in Europe from 20.8/1000 births in 1997 increasing to 25.4/ 1000 births in $2018 .{ }^{17}$ EUROCAT included both livebirth and non-livebirth pregnancies past 20 weeks of gestation, and terminations of pregnancy due to identified major malformations (TOPFA) at any gestational age. Danish data reported to EUROCAT were based on data from women residing on Funen, and showed a fluctuating trend from 25.1 in 1997 to $25.0 / 1000$ births in 2017 , with a peak of $35.9 / 1000$ births in $2006 .{ }^{17}$

The objective of this study was to describe the prevalence and changes in registration of malformations among pregnancies in the Danish nationwide registers from 1997 to 2017. We also aimed to provide a guide for other researchers to identify major malformations in the Danish Health Registries, using a Danish adaptation of the EUROCAT classification.

\section{Methods}

Using the Danish National Health Registers, we performed a descriptive, nationwide study identifying all recorded pregnancies in Denmark from 1997 to 2017. Pregnancies covered included livebirths, stillbirths or late miscarriages from 20 weeks of gestation, and TOPFA at any gestational age. We translated the EUROCAT definition of major and minor malformation to describe the population regarding overall malformations and organ specific subgroups.

\section{Data Source}

Due to the tax-funded Danish health care system, pregnancy and maternity care is free of charge with mandatory reporting to national health authorities. All inhabitants in Denmark are assigned a unique personal identification number at birth or first immigration which allows for linkage between multiple individual level administrative registers. ${ }^{18}$

The Danish National Patient Registry (the Patient register) was established in 1978 and contains data on all hospital contacts, including but not limited to diagnoses, procedures, and dates related to each contact. ${ }^{19}$ We identified data on terminations, miscarriages, deliveries, antenatal ultrasound scans, as well as gestational age at the time of contact, and any malformation diagnoses related to each appointment. Diagnoses are coded according to the International Classification of Diseases, version 10 (ICD10) codes with a Danish extension for specific malformations.

The Register of Legally Induced Abortions (the Abortion register) was established in 1973 and contains information on all terminations of pregnancy in Denmark regardless of setting. In hospital terminations are reported to the Patient register and subsequently extracted to the Abortion register. Terminations in other settings including private clinics are reported directly to the Abortion register.

The Danish Medical Birth Register (the Birth register) was established in 1973 and contains information on all births in Denmark regarding maternal characteristics and specific variables on pregnancy, delivery, and information on outcomes. ${ }^{20}$ The Birth register includes information on all livebirths regardless of gestational age, and since April 2004 stillbirths after 21 full gestational weeks. Prior to April 2004, the cut-off between miscarriage and stillbirth was 28 full gestational weeks. Livebirths were followed during the first five years of life or until death, whichever occurred first. The Danish Register of Causes of Death (the Cause of Death register) was established in 1875 and informs on date and cause of death classified according to ICD10 codes since $1994 .{ }^{21}$

\section{Study Population}

To capture all malformation records regardless of the outcome of pregnancy (TOPFA, non-livebirth after 20 weeks of gestation, or livebirth), we identified all women with a recorded pregnancy from January 1, 1997 to December 31, 2017. TOPFAs of any gestational age were identified in the Abortion register and the Patient register. Non-livebirths with a gestational duration past 20 weeks (miscarriages and 
stillbirths) were identified from the Patient register and the Birth register. All livebirths were identified by delivery records from the Birth register regardless of gestational age. To enable comparison with EUROCAT, we excluded terminations without a marker or diagnosis of foetal malformations and miscarriages before 20 weeks of gestation. To increase the follow-up of livebirths, we excluded pregnancies with emigration during the first postnatal year. Exclusions and final study population are illustrated in Figure 1.

\section{Malformation Data Sources}

Malformation records were identified using maternal records during pregnancy from the Patient and Abortion register, as well as children's records during the first five years of life from the Birth register, the Patient and Cause of Death register. Malformation records with a primary diagnose of suspected disease (ICD-10: Z03) or a supplementary diagnosis of "DUM02 - malformation, ruled out" were disregarded. To restrict maternal records to diagnoses regarding the foetus, maternal records from the Patient and Abortion register were limited to records with a primary diagnosis of O00-O08 Pregnancy with abortive outcome, O28 Abnormal findings on antenatal screening of mother, O35 Maternal care for known or suspected foetal abnormality and damage, or Z36 antenatal screening.

The Birth register are limited to malformations within the ICD-10 Q-chapter, but also includes malformations recorded among stillbirths and home deliveries which are not recorded elsewhere. Around 180 pregnancies were registered with a numeric malformation indicator rather than a specific ICD-10 code in the Birth register. These were disregarded. Malformation codes outside the Q-chapter were identified in the Patient register, the Abortion register, and Cause of Death register. The date of diagnosis and information on diagnostic specialist doctor could only be identified in the Patient register.

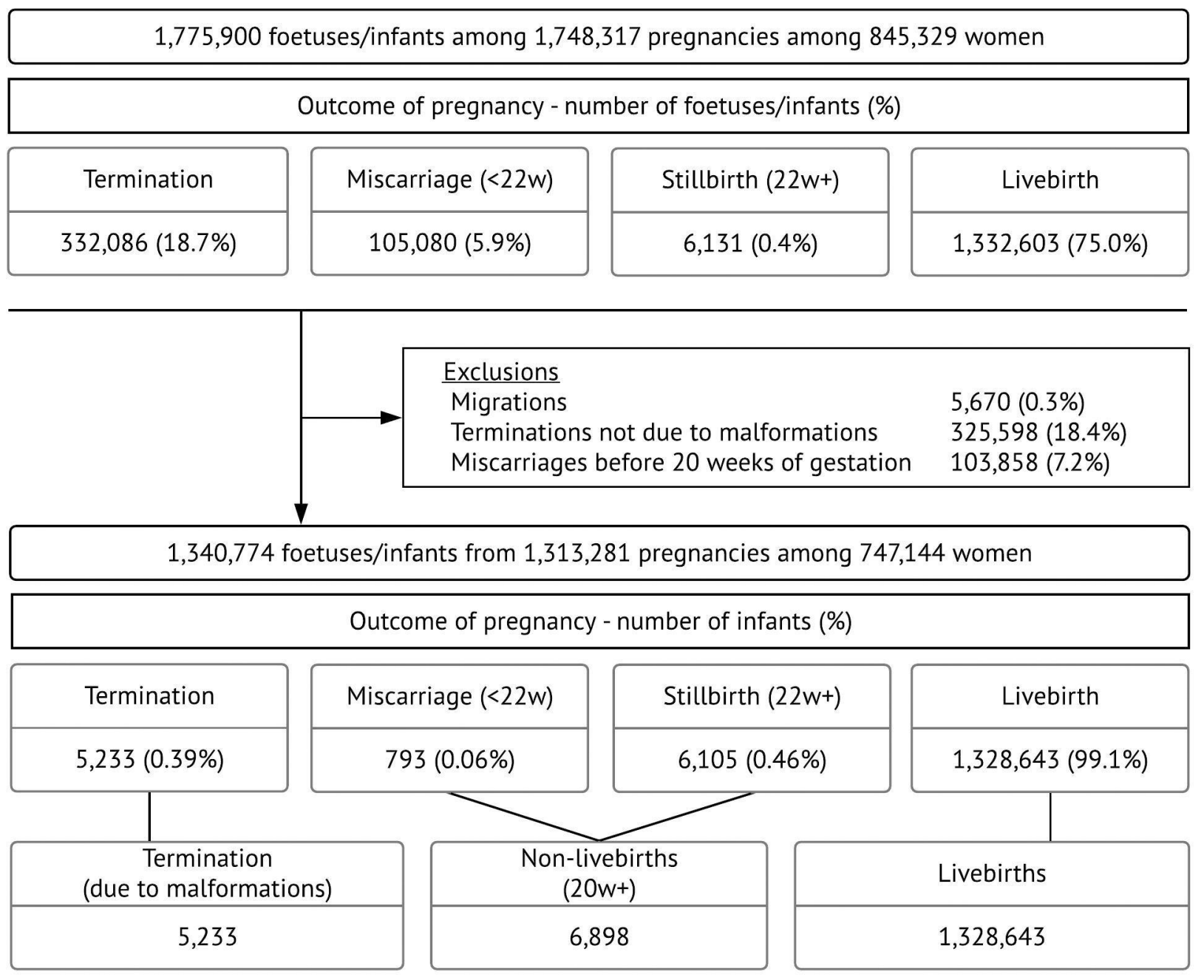

Figure I Flowchart of exclusions and final study population by outcome of pregnancy. 
Malformation records in the Patient register, the Abortion register, and the Birth register were categorised as primary (main reason for contact), secondary (additional information about the primary diagnosis), supplementary (extra information ie, gestational age at contact or specific malformation code), tentative (suspected unconfirmed diagnosis), or referrals (unconfirmed diagnosis). Prenatal malformation diagnoses in maternal records during pregnancy for non-livebirths and TOPFA were included in all analyses regardless of restriction applied to postnatal records.

\section{Malformation Definitions}

We identified "Any malformation" records defined as ICD10 codes from chapter Q (Congenital malformations, deformations, and chromosomal abnormalities), D18.1A (Cystic hygroma), D21.5 (Sacral teratoma), D82.1 (Pharyngeal pouch syndrome), P35.0 (Fetal rubella syndrome), P35.1 (Fetal cytomegalovirus syndrome), and P37.1 (Fetal toxoplasmosis) in line with EUROCAT overall inclusion criteria. Major malformations were identified by excluding minor malformations based on the EUROCATs classification of malformations. ${ }^{22}$

EUROCAT is based on the British Pediatrics Association's one-digit extension of the ICD-10 classification (BPA-ICD-10) which have small discrepancies with the one-character extension used in Denmark (DK-ICD-10). A direct translation was not possible for all malformations. An example of a translatable discrepancy was "Persistent right aortic arch" which was coded as Q25.41 in the BPAICD-10 and as Q25.4E in the DK-ICD-10. Conversely, "Congenital constriction bands" coded as Q79.80 in BPAICD-10 did not have an equivalent Danish code. The nearest Danish code was "amnion bands" O41.8A which was not included in malformation classifications. A full list of discrepancies between the British Pediatric Association's subclassification of ICD-10 and the Danish classifications are listed in Supplementary Digital Content 1. A full list of ICD-10-DK inclusion and exclusion codes for EUROCAT defined major malformations as well as organsystem-based groupings can be found in Supplementary Digital Content 2.

\section{Danish Malformation Data Reported to EUROCAT}

The Danish EUROCAT data are based on pregnancies by women residing on Funen or surrounding islands covering
$7-8 \%$ of the national deliveries each year. Cases are manually identified using discharge and outpatient records from obstetric and paediatric departments and clinics, as well as procedures and examinations performed on identified cases during the first 5 years of life. Infants with only minor malformations are not included. ${ }^{23}$ In addition to restrictions on diagnostic specialist doctor and type of diagnosis (primary or secondary discharge and outpatient records), major hip malformations are restricted to cases still present, ie, coded, more than six weeks after birth. The Danish postnatal examination of the new-born includes screening for hip dysplasia ${ }^{24}$ leading to $1-2 \%$ of all livebirths being referred for further examination or ultrasound. ${ }^{25}$

\section{Descriptive Analysis}

To illustrate the distribution of malformation records in the Danish registries, we tabulated any major malformation records from different registries. Minor congenital malformations are more common but have less medical, functional, and cosmetic consequences than major malformations. Cases with minor malformations only were unaccounted for in the remaining analyses. We calculated the overall and annual prevalence of major malformations per 1000 pregnancies using different restriction criteria: 1) unrestricted data included any records of a major malformation regardless of type of record; 2) data restricted to primary and secondary diagnoses included discharge and outpatient records from postnatal records, malformations registered as a cause of death, and selected supplementary maternal records during pregnancy; 3) in line with EUROCAT guidance, we performed further analyses restricting to major hip malformation records to cases present after six weeks postnatally, and 4) diagnoses by a specialist doctor; and 5) in an attempt to restrict hip malformations on number of contacts as a proxy for severity, we did separate analyses excluding major hip malformations with less than two separate records regardless of gestational age.

To identify cases reported to EUROCAT, we identified primary and secondary diagnoses from obstetric and paediatric specialists during pregnancy or first five years of life among women and offspring residing on Funen or surrounding islands during the study period. Major hip malformations were restricted to cases present six weeks after birth. The algorithm was then applied to the national dataset. 
To illustrate trends in prevalence by organ specific malformation group, we calculated the annual prevalence of major malformations for each of the 15 malformation groups defined by EUROCAT. ${ }^{22}$ Among identified major malformations, we calculated the prevalence of primary and secondary records of the 10 most common major malformation diagnoses defined by ICD-10 level 3 (ie, Q65 hip malformation) excluding any minor malformation subgroups.

To describe time from delivery to malformation diagnosis during the first five years of life, we illustrated the prevalence of major malformations at delivery, 1, 3, 6, and 12 months, and 2, 3, 4, and 5 years after delivery stratified in 5-year strata. This depiction was based on records from the Patient register alone, as date of diagnose was only available in the register.

\section{Other}

The study is purely register-based, and according to Danish law no ethical permission is needed. The project was registered at the Danish Data Protection repository of Odense University Hospital (journal no. 19/36,067). The project was funded by the Novo Nordic Foundation. Grant number NNF17OC0028866.

\section{Results}

We included 1,340,774 foetuses/infants from 1,313,281 pregnancies by 747,144 women from 1997 to 2017 (Figure 1). The prevalence of congenital malformations varied greatly depending on the data sources included and the choice of diagnosis type. The prevalence of any major malformations by outcome in each data source with different restrictions are illustrated in Table 1 . We identified 108,013 cases with major malformations (81/ 1000 foetuses/infants) in the unrestricted dataset, of which $5360(4 / 1000)$ were recorded during pregnancy and 102,744 (77/1000) had postnatal records. When restricting data from postnatal records to primary and secondary diagnoses the prevalence was reduced to 62,576 (47/1000). Further restrictions for major hip malformation records after 6 weeks post-partum and diagnosis by a specialist doctor, reduced the numbers to $59,695(45 / 1000)$ and 43,198 (32/1000), respectively (Table 1).

We found an increase in annual prevalence of major malformations in all five levels of data restriction. Unrestricted data revealed a steep increase in cases from 49/1000 in 1997 to $101 / 1000$ in 2014 after which data were likely to be underreported due to late diagnosis and lack of follow-up. Restrictions on primary and secondary diagnosis records, and for major hip malformations a minimum of two records or records after 6 weeks postpartum, all revealed similar annual prevalence outputs, however lower than the unrestricted data. Further restriction to records by specialist doctors reduced the annual prevalence from $28 / 1000$ in 1997 to $40 / 1000$ in 2014 (Figure 2).

When mimicking restrictions to match cases reported to EUROCAT, we found a similar annual prevalence of malformations among non-livebirths and TOPFA but found a greater increase in cases among livebirths when compared to Danish EUROCAT contributions (Figure 3A). Annual prevalence of major malformations increased from $1883(27.6 / 1000)$ in 1997 to $2630(45.3 / 1000)$ in 2014 when using the same restrictions on national data (Figure 3B). For direct comparison, cases reported to EUROCAT data from the Danish registries are illustrated in Figure $3 \mathrm{C}^{23}$

Using the restriction criteria of primary and secondary diagnoses, and hip malformations present 6 weeks after birth, the most common major malformation groups were heart defects and limb malformations. Heart malformations increased during the period from $10 / 1000$ in 1998 to $15 / 1000$ in 2015 . Limb malformations fluctuated between 76 and 101/1000 from 1997 to 2016. Urinary malformation cases almost tripled from $27 / 1000$ in 1997 to $76 / 1000$ in 2014. Oro-facial clefts malformations decreased slightly during the period. Over time, all remaining malformations groups increased although they continued to be very rare with a prevalence rate under $5 / 1000$ throughout the period (Figure 4 and Table 2). For individual malformation defined by ICD-10 level 3, malformations of cardiac septa (Q21) and great arteries (Q25) were the most common major malformations with a peak of 10 and $6 / 1000$ births in 2010 and 2009, respectively. Obstructive defects of renal pelvis and malformations of ureter (Q62), hypospadias (Q54), and other malformations of skull and face bones (Q75) increased during the period and all had a prevalence of 3-4/1000 in 2017 (Figure 5).

Using the restriction criteria of primary and secondary diagnoses, and hip malformations present 6 weeks after birth, only 16/1000 livebirths had a major malformation record on the date of delivery in 2017. 32/1000 livebirths had a diagnosis within the first three months, and 42/1000 
Table I Congenital Malformation Diagnoses in Maternal and Infant Records from Different Registries Applying Different Restrictions to Types of Diagnoses. Each Infant/Fetus Was Only Represented Once per Register or Definition

\begin{tabular}{|c|c|c|c|c|}
\hline & Livebirth & $\begin{array}{l}\text { Non- } \\
\text { Livebirth }\end{array}$ & TOPFA & All \\
\hline \multirow[t]{2}{*}{ Total infants/foetuses } & $\mathrm{I}, 328,643$ & 6898 & 5233 & $\mathrm{I}, 340,774$ \\
\hline & \multicolumn{4}{|c|}{$\begin{array}{l}\text { Identification of cases with one or more congenital malformation } \\
\text { records }\end{array}$} \\
\hline \multirow[t]{2}{*}{ Data source } & \multicolumn{4}{|c|}{ Any malformation records/Specified major malformations } \\
\hline & Any/Specific & Any/Specific & $\begin{array}{l}\text { Any/ } \\
\text { Specific }\end{array}$ & Any/Specific (\%) \\
\hline $\begin{array}{l}\text { Birth register }{ }^{\mathrm{a}} \\
\text { Main register } \\
\text { Primary/secondary diagnoses } \\
\text { Homebirth forms } \\
\text { Stillbirth forms }\end{array}$ & $\begin{array}{l}85,204 / 55,336 \\
85,163 / 55,305 \\
71,470 / 44,299 \\
99 / 70\end{array}$ & $\begin{array}{l}408 / 365 \\
\mathrm{n}<5 * \\
\mathrm{n}<5 \\
\mathrm{n}<5 \\
404 / 362\end{array}$ & & $\begin{array}{l}85,612 / 55,701(4.2) \\
85,166 / 55,308 \\
71,473 / 44,302 \\
100 / 70 \\
404 / 362\end{array}$ \\
\hline Cause of Death register ${ }^{b}$ & $1730 / 1704$ & $\mathrm{n}<5$ & & $1732 / 1706(0.1)$ \\
\hline $\begin{array}{l}\text { Patient register (child) })^{\text {b,e }} \\
\text { Tentative diagnoses } \\
\text { Primary/secondary diagnoses } \\
\text { + hip malformations with two or more records } \\
\text { + hip malformations present after } 6 \text { weeks postpartum } \\
\text { + by specialist doctor } \\
\text { + by specialist doctor } \\
\text { c \& hip malformations present after } 6 \\
\text { weeks postpartum }\end{array}$ & $\begin{array}{l}|6|, 70|/| 10 \mid, 997 \\
30,858 /|9,| 48 \\
1 \mid 2,960 / 61,846 \\
103,650 / 58,363 \\
108,44|/ 59,07| \\
70, \mid 86 / 44,594 \\
68,447 / 43,192\end{array}$ & $\begin{array}{l}11 / 8 \\
n<5 \\
10 / 7 \\
10 / 7 \\
10 / 7 \\
7 / 6 \\
7 / 6\end{array}$ & & $\begin{array}{l}161,7 \mid 2 / 102,005(7.6) \\
30,859 / 19,149 \\
1 \mid 2,970 / 61,853 \\
103,660 / 58,370 \\
108,451 / 59,078 \\
70,193 / 44,600 \\
68,454 / 43,198\end{array}$ \\
\hline $\begin{array}{l}\text { Patient register (mother) } \\
\text { Included }^{d}\end{array}$ & $7548 / 7163$ & $\begin{array}{l}296 / 285 \\
296 / 285\end{array}$ & $\begin{array}{l}4927 / 4782 \\
4927 / 4782\end{array}$ & $\begin{array}{l}|2,77| / \mid 2,230 \\
5223 / 5067(0.4)\end{array}$ \\
\hline Abortion register & & $\mathrm{n}<5$ & $5233 / 5055$ & $5234 / 5056(0.4)$ \\
\hline All unrestricted sources combined & $162,028 / 102,373$ & $608 / 565$ & $5233 / 5075$ & $167,869 / 108,013(8.1)$ \\
\hline $\begin{array}{l}\text { Prenatal records } \\
\text { Postpartum records }\end{array}$ & $\mid 62,028 / 102,373$ & $\begin{array}{l}296 / 285 \\
4|7 / 37|\end{array}$ & $5233 / 5075$ & $\begin{array}{l}5529 / 5360(0.4) \\
162,445 / 102,744(7.7)\end{array}$ \\
\hline
\end{tabular}

Notes: *According to Danish confidentiality laws, reporting specific counts below five is not allowed. ${ }^{\mathrm{a} O n e-y e a r ~ f o l l o w-u p ~ i n ~ t h e ~ B i r t h ~ r e g i s t e r . ~}{ }^{\mathrm{b}}$ Livebirths were followed for up to five years. 'Specialist doctors included pediatricians and obstetricians (specialist code 80 and 38). 'Maternal records during pregnancy were disregarded for livebirths. ${ }^{e}$ Data on timing and specialist doctor were only available in the Patient register.

within the first year (Figure 6). The prevalence of malformation records over time were similar by region of Denmark (data not shown).

Post hoc analyses of limb malformations showed a majority of hip malformations (Q65) and the prevalence was strongly associated with the choice of inclusion criteria. Supplementary Digital Content 3 outlines annual prevalence of major hip malformations using different criteria.

Using the restriction criteria of primary and secondary diagnoses, and hip malformations present 6 weeks after birth, 65,411 (49/1000 foetuses/infants) had a recorded major malformation. Of these, 40,142 were captured in the Birth register, and 1706 in the Cause of Death register. Records from the Patient register yielded 59,078 cases in children's records and 5067 in maternal records, and records from the Abortion register contained 5056 cases with major malformations.

\section{Discussion}

We demonstrate that the rates of congenital malformations identified through the Danish Birth register, the Patient register, the Abortion register, and the Cause of Death register over the last 21 years is highly dependent on the applied definition of malformations. The overall prevalence of major malformations increased slightly over the study 


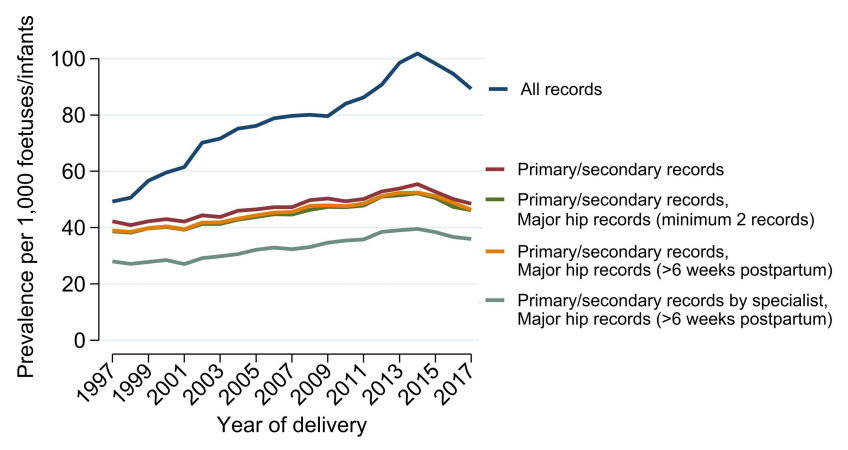

Figure 2 Major malformation prevalence per 1000 foetuses/infants per year using different inclusion criteria for livebirth records. Data sources included the Birth register, children and maternal records from the Patient register, the Abortion register, and the Cause of Death register. All records included any type of diagnosis; primary/secondary records included discharge or outpatient diagnoses, tentative diagnoses were excluded; primary/secondary records, major hip records (minimum 2 records), added a further restriction of minimum 2 records for major hip records; primary/secondary records, major hip records (>6 weeks postpartum), included primary/secondary records added a further restriction of diagnose after 6 weeks postpartum for major hip malformations; primary/secondary records by specialist, major hip records (>6 weeks postpartum), included primary and secondary diagnoses by an obstetrician or paediatrician, added a restriction of diagnoses after 6 weeks postpartum for major hip malformations.

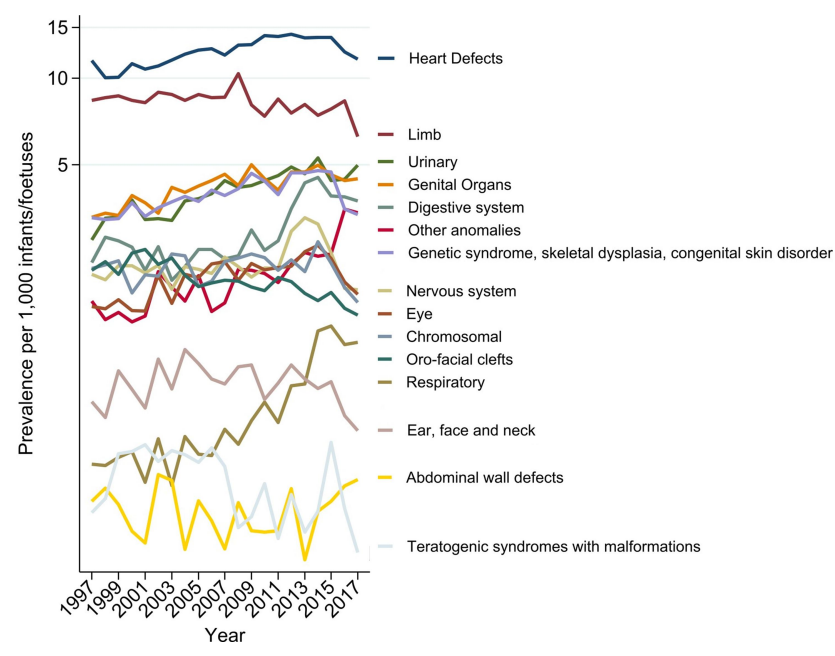

Figure 4 Annual prevalence of major malformation groups defined by EUROCAT, restricted to primary and secondary diagnose records. Data sources included the Birth register, children and maternal records from the Patient register, the Abortion register, and the Cause of Death register. Note logarithmic y-axis.

period. The increase was seen for most organ specific malformation groups as defined by EUROCAT. Based on this study, we recommend identifying major malformations using primary and secondary diagnoses from children's records in the Patient register and the Cause of Death register, merged with records from the Birth register to identify biological link between mother and child. Major malformations among non-livebirths and TOPFA should be identified in the Patient register and the Abortion register. We advise to restrict major hip malformations to only include those with records after 6 weeks post-partum in


Figure 3 Annual prevalence of major malformation per 1000 foetuses/infants. (A) Study population restricted to Funen and surrounding islands to reflect the catchment area for EUROCAT reports. (B) Restrictions from (A) applied to the nationwide study population. (C) Danish data as reported to EUROCAT. Malformation records were restricted to primary and secondary diagnoses by specialist doctors for livebirths, and supplementary diagnoses from maternal records for nonlivebirths and TOPFA. Data sources included the Birth register, children and maternal records from the Patient register, the Abortion register, and the Cause of Death register.

the Patient register. Finally, we advise to use the Danish adaptation of EUROCAT supplied in this paper.

The major strength of our study is the nationwide approach with access to all relevant registers comprising all relevant records of any malformation. As the Danish health care system is free of charge and registration of 
Table 2 Annual Major Malformation Prevalence by EUROCAT Group

\begin{tabular}{|c|c|c|c|c|c|}
\hline & 1997 & 2002 & 2007 & 2012 & 2017 \\
\hline \multirow[t]{2}{*}{ All foetuses/infants } & 68,247 & 64,749 & 65,079 & 59,069 & 62,577 \\
\hline & \multicolumn{5}{|c|}{$N($ per 1000) } \\
\hline With Major malformations & 2649 (39) & $286 I(44)$ & 3197 (49) & $3386(57)$ & 3291 (53) \\
\hline Nervous system & $145(2.1)$ & $195(3)$ & $220(3.4)$ & $25 I(4.2)$ & $208(3.3)$ \\
\hline Eye & $110(1.6)$ & $134(2.1)$ & $150(2.3)$ & $|3|(2.2)$ & $110(1.8)$ \\
\hline Ear, face and neck & $51(0.8)$ & $69(1.1)$ & $64(1.0)$ & $103(1.7)$ & $38(0.6)$ \\
\hline Heart Defects & $781(11)$ & $716(11)$ & $797(12)$ & $879(15)$ & $783(13)$ \\
\hline Respiratory & $31(0.5)$ & $39(0.6)$ & $45(0.7)$ & $53(0.9)$ & $77(1.2)$ \\
\hline Oro-facial clefts & I 46 (2.I) & $146(2.3)$ & $135(2.1)$ & $|2|(2)$ & $96(1.5)$ \\
\hline Digestive system & $155(2.3)$ & $175(2.7)$ & $160(2.5)$ & $219(3.7)$ & $243(3.9)$ \\
\hline Abdominal wall defects & $23(0.3)$ & $31(0.5)$ & $23(0.4)$ & $31(0.5)$ & $47(0.8)$ \\
\hline Urinary & I $86(2.7)$ & $229(3.5)$ & $300(4.6)$ & $315(5.3)$ & $334(5.3)$ \\
\hline Genital Organs & $227(3.3)$ & $221(3.4)$ & $306(4.7)$ & $283(4.8)$ & $280(4.5)$ \\
\hline Limb & $566(8.3)$ & $578(8.9)$ & $566(8.7)$ & $464(7.9)$ & $406(6.5)$ \\
\hline Other anomalies & $115(1.7)$ & $138(2.1)$ & $112(1.7)$ & $137(2.3)$ & $225(3.6)$ \\
\hline Genetic syndromes, skeletal dysplasia, congenital skin disorders & $222(3.3)$ & $234(3.6)$ & $258(4)$ & $284(4.8)$ & $220(3.5)$ \\
\hline Teratogenic syndromes & $21(0.3)$ & $30(0.5)$ & $30(0.5)$ & $22(0.4)$ & $15(0.2)$ \\
\hline Chromosomal & $148(2.2)$ & $204(3.2)$ & $266(4.1)$ & $325(5.5)$ & $307(4.9)$ \\
\hline
\end{tabular}

major congenital malformations are mandatory, the risk of selection bias is low. Our approach describes the content of malformation records in the national registers and qualify a transparent approach to identify malformation diagnoses by merging information from health-care registers.

The principal limitations all relate to the validity of coding of malformations. First, the validity of the malformation diagnoses remains largely undocumented. Secondly, despite mandatory reporting we do not know the extent to which major malformations may go unreported. Finally, referrals for tentative malformations are increasingly common, and differentiation between suspected and confirmed diagnoses can be difficult to identify in the registries.

Our findings have important implications for epidemiological research on congenital malformations. The wide range of malformation rates reported in previous studies and reports are very likely to be an indication of using different definitions and algorithms to define malformations. Currently, the Birth register extracts all hospital

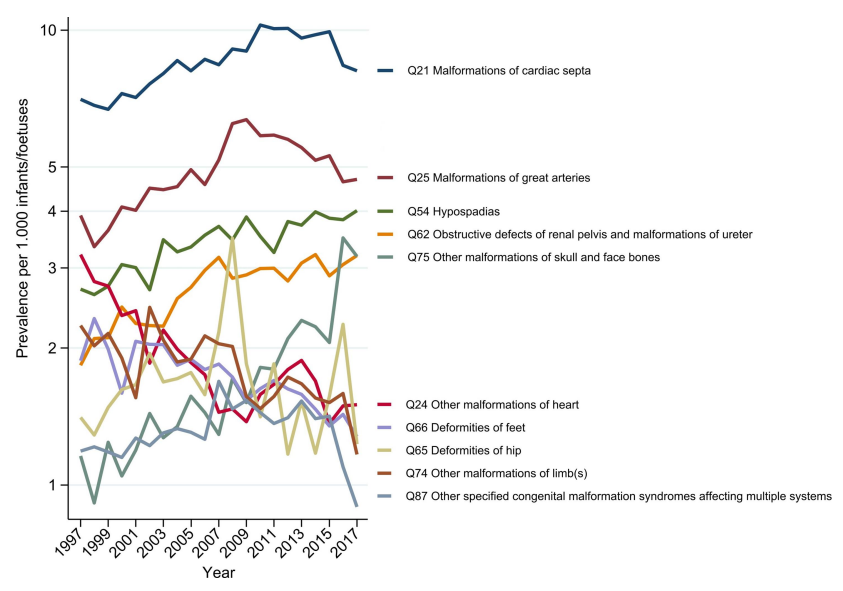

Figure 5 Ten most common major malformations in Denmark (ICD-10 level 3). Data sources included the Birth register, children and maternal records from the Patient register, the Abortion register, and the Cause of Death register. Note logarithmic $y$-axis.

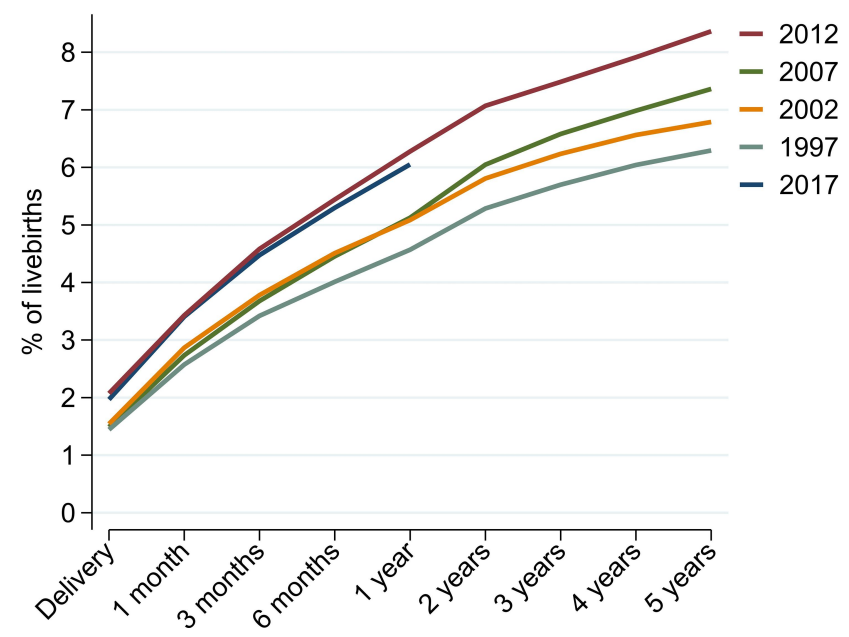

Figure 6 Prevalence of major malformation records during the first five years of life, stratified by year of end of pregnancy. 
records with an ICD-10 Q code within the first year of life from the Patient register and do not distinguish between major and minor malformations. The Birth register furthermore includes all malformations from stillbirths and homebirths. The latter is not found in any other register, however only a few infants with major malformations were not registered during follow-up in the Patient register.

For comparison, the EUROCAT includes malformations from other ICD-10 chapters but disregard all minor malformations as classified by British Paediatrics Association. ${ }^{24}$ Change in coding practices and/or better diagnosing during the last two decades may in part explain the increase in malformation cases as suggested by the Danish Health Authority. ${ }^{14}$

Our findings also have some clinical implications. The results show a slight increase in the rate of major malformations during the last two decades, although not nearly as steep as suggested by unrestricted data. An increasing gap between defining a major malformation as one or two record(s) could indicate that health care professionals have become more likely to code suspicion of malformations than previously as there is an increased focus on errors and liability in the health care system.

The predictive value of a clinical diagnosis of some hip malformations is notoriously poor. This is specifically relevant to a "clicking hip" which is clinical diagnosis originating from a widely used post-natal routine screening procedure. $^{25,26}$ The extent to which such poorly validated clinical procedures result in recording of a malformation diagnosis in Danish registries is not known. Our results suggest that initial screenings substantially overrepresent certain types of hip "malformations" as witnessed by a series of restrictions applied to this group of malformations (Supplementary Digital Content 3). Poorly specified anomalies include clicking hip, clubfoot with no further specification, undescended testis, unspecified ectopic testis, functional or unspecified cardiac murmur, functional gastro-intestinal disorders, and laryngomalacia and tracheomalacia. ${ }^{27}$ Studies including these outcomes, should be interpreted with caution.

\section{Conclusion}

Register data on congenital malformations appear susceptible to changes in technical coding practices and may be biased from reporting of poorly validated clinical diagnoses.
To increase the validity of epidemiological studies of major malformations using Danish health registries, we recommend using primary and secondary diagnoses from both the Birth register and children records from the Patient register and the Cause of Death register. Maternal records in the Patient register and the Abortion register should be used to identify malformations during pregnancy, and this is the only source of malformations for non-livebirths and TOPFA. Major malformations should be defined using the Danish translation of the EUROCAT classification provided in this article. Major hip malformations should only include those present after 6 weeks post-partum.

\section{Disclosure}

Per Damkier reports grants from Novo Nordic Foundation, during the conduct of the study. The authors report no other potential conflicts of interest for this work.

\section{References}

1. Fedder J, Loft A, Parner ET, Rasmussen S, Pinborg A. Neonatal outcome and congenital malformations in children born after ICSI with testicular or epididymal sperm: a controlled national cohort study. Hum Reprod. 2013;28(1):230-240. doi:10.1093/humrep/des 377

2. Sass L, Urhoj SK, Kjærgaard J, Dreier JW, Strandberg-Larsen K, Nybo Andersen A-M. Fever in pregnancy and the risk of congenital malformations: a cohort study. BMC Pregnancy Childbirth. 2017;17 (1):413. doi:10.1186/s12884-017-1585-0

3. Frederiksen LE, Ernst A, Brix N, et al. Risk of adverse pregnancy outcomes at advanced maternal age. Obstet Gynecol. 2018;131 (3):457-463. doi:10.1097/AOG.0000000000002504

4. Ehrenstein V, Kristensen NR, Monz BU, Clinch B, Kenwright A, Sørensen HT. Oseltamivir in pregnancy and birth outcomes. BMC Infect Dis. 2018;18(1):519. doi:10.1186/s12879-018-3423-z

5. Damkier P, Brønniche LMS, Korch-Frandsen JFB, Broe A. In utero exposure to antibiotics and risk of congenital malformations: a population-based study. Am J Obstet Gynecol. 2019;221(6):648.e1648.e15. doi:10.1016/j.ajog.2019.06.050

6. Thomseth V, Cejvanovic V, Jimenez-Solem E, Poulsen HE, Utheim TP, Andersen JT. Exposure to antazoline-naphazoline eye drops during pregnancy and the risk of congenital malformations: a Danish nationwide cohort study. Acta Ophthalmol. 2019;97 (5):505-509. doi:10.1111/aos. 13980

7. Grønbaek L, Vilstrup H, Jepsen P. Pregnancy and birth outcomes in a Danish nationwide cohort of women with autoimmune hepatitis and matched population controls. Aliment Pharmacol Ther. 2018;48 (6):655-663. doi:10.1111/apt.14925

8. Torp-Pedersen A, Jimenez-Solem E, Cejvanovic V, Poulsen HE, Andersen JT. Birth outcomes after exposure to mebendazole and pyrvinium during pregnancy - a Danish nationwide cohort study. J Obstet Gynaecol. 2016;36(8):1020-1025. doi:10.1080/01443615. 2016.1178222

9. Nørgaard M, Nielsson MS, Heide-Jørgensen U. Birth and neonatal outcomes following opioid use in pregnancy: a Danish population-based study. Subst Abuse Res Treat. 2015;9(Suppl 2):5-11. doi:10.4137/SART.S23547 
10. Damkier P, Broe A. First-trimester pregnancy exposure to modafinil and risk of congenital malformations. JAMA. 2020;323(4):374-376. doi:10.1001/jama.2019.20008

11. Pasternak B, Svanström H, Mølgaard-Nielsen D, Melbye M, Hviid A. Metoclopramide in pregnancy and risk of major congenital malformations and fetal death. JAMA. 2013;310(15):1601-1611. doi:10.10 01/jama.2013.278343

12. The Danish Health Authority [Sundhedsdatastyrelsen]. Congenital malformations among livebirths [Medfødte misdannelser hos levendefødte børn]; 2019. Available from: https://sundhedsdatastyrel sen.dk/da/tal-og-analyser/analyser-og-rapporter/kort_nyt. Accessed October 12, 2020.

13. Langhoff-Roos J, Krebs L, Klungsøyr K, et al. The nordic medical birth registers-a potential goldmine for clinical research. Acta Obstet Gynecol Scand. 2014;93(2):132-137. doi:10.1111/aogs.12302

14. Kristensen J, Langhoff-Roos J, Skovgaard LT, Kristensen FB. Validation of the Danish birth registration. J Clin Epidemiol. 1996;49(8):893-897. doi:10.1016/0895-4356(96)00018-2

15. Infertility, infertility treatment, and congenital malformations: Danish national birth cohort. PubMed - NCBI. Available from: https://www. ncbi.nlm.nih.gov/pubmed/?term=Infertility\%2C+infertility+treatment + and + congenital + malformations $\% 3 \mathrm{~A}+\mathrm{Danish}+$ national+birth +cohort.+BMJ. Accessed November 18, 2019.

16. Weatherall J, Lechat M, Ayme S, Dolk H. EUROCAT network history and funding: 1 .

17. European Platform on Rare Disease Registration. Available from: https://eu-rd-platform.jrc.ec.europa.eu. Accessed October 5, 2020.

18. Pedersen CB. The Danish civil registration system. Scand $J$ Public Health. 2011;39(7 Suppl):22-25. doi:10.1177/ 1403494810387965
19. Lynge E, Sandegaard JL, Rebolj M. The Danish national patient register. Scand J Public Health. 2011;39(7 Suppl):30-33. doi:10.11 77/1403494811401482

20. Bliddal M, Broe A, Pottegård A, Olsen J, Langhoff-Roos J. The Danish medical birth register. Eur J Epidemiol. 2018;33(1):27-36. doi:10.1007/s10654-018-0356-1

21. Helweg-Larsen K. The Danish register of causes of death. Scand J Public Health. 2011;39(7 Suppl):26-29. doi:10.1177/140349481 1399958

22. EUROCAT-guide-1.4-full-guide.pdf. Available from: http://www. eurocat-network.eu/content/EUROCAT-Guide-1.4-Full-Guide.pdf. Accessed September 3, 2015.

23. European Platform on Rare Disease Registration. Odense Registry. Available from: https://eu-rd-platform.jrc.ec.europa.eu/eurocat/euro cat-members/registries/Odense_en. Accessed October 22, 2020.

24. Anbefalinger-for-svangreomsorgen.pdf. Available from: https://www. sst.dk/da/udgivelser/2015//-/media/Udgivelser/2015/Anbefalingersvangreomsorgen/Anbefalinger-for-svangreomsorgen.ashx. Accessed March 25, 2020.

25. Lægehåndbogen - Hofteledsdysplasi - sundhed.dk. Available from: https://www.sundhed.dk/sundhedsfaglig/laegehaandbogen/paediatri/ tilstande-og-sygdomme/ortopaedi/hoftedysplasi-hos-boern/. Accessed October 12, 2020.

26. Patel H. Canadian Task Force on Preventive Health Care. Preventive health care, 2001 update: screening and management of developmental dysplasia of the hip in newborns. CMAJ Can Med Assoc J J Assoc Medicale Can. 2001;164(12):1669-1677.

27. European Commission. Guideline for data registration. Available from: https://eu-rd-platform.jrc.ec.europa.eu/eurocat/data-collection/ guidelines-for-data-registration_en. Accessed August 1, 2020.
Clinical Epidemiology

\section{Publish your work in this journal}

Clinical Epidemiology is an international, peer-reviewed, open access, online journal focusing on disease and drug epidemiology, identification of risk factors and screening procedures to develop optimal preventative initiatives and programs. Specific topics include: diagnosis, prognosis, treatment, screening, prevention, risk factor modification, systematic reviews, risk \& safety of medical interventions, epidemiology \& biostatistical methods, and evaluation of guidelines, translational medicine, health policies \& economic evaluations. The manuscript management system is completely online and includes a very quick and fair peer-review system, which is all easy to use.

\section{Dovepress}

